\title{
An insight into prescription drugs and medicine on the AlphaBay cryptomarket
}

\author{
Morelato M..$^{\mathrm{b}}$, Medeiros Bozic S. a,b, Rhumorbarbe D.a, , Broséus J.a, \\ Staehli L.a, Esseiva P.a, Roux C.b, Rossy Q.a, \\ aEcole des Sciences Criminelles, University of Lausanne, Lausanne, Switzerland. \\ bCenter for forensic sciences, University of Technology, Sydney, Australia.
}

\begin{abstract}
Internet access has provided new ways to trade goods. Unlike conventional legal sale sites, cryptomarkets facilitate exchanges in a context where the anonymity of participants is warranted. The aim of this article was to obtain a better understanding of the trafficking of prescription drugs and medicine on the AlphaBay cryptomarket. The results showed that alprazolam, oxycodone, and Adderall were the most offered prescription drugs while alprazolam, diazepam, and oxycodone were the most sold substances. The sale was dominated by North America, Australia, and Western European countries. The revenue of prescription drugs was estimated to be more than US\$65 million since the creation of AlphaBay, a small market in comparison with the worldwide legal pharmaceutical market's estimate of US\$1.3 trillion in 2020. Digital traces offer a complementary way to understand the trafficking of prescription drugs and medicine and to identify the most prolific vendors and their implication in this trafficking.
\end{abstract}

Keywords: forensic intelligence; digital trace; revenue; geographical analysis.

\section{Introduction}

The Internet has created new ways to trade licit and illicit commodities as well as to exchange information. Online platforms operating in the legal economy have had an impact on business models, customers and vendors. This development has been mirrored in the illicit trade as it provides criminals with opportunities to grow their businesses since they can reach a large number of potential customers around the world (Décary-Hétu \& Aldridge, 2015; Europol, 2017; Martin, 2014a). The sale of prescription drugs and medicine, as well as false and counterfeit medicines has also been facilitated by the Internet (European Monitoring Centre for Drugs and Drug Addiction, 2016; Gelatti et a1., 2013; Inciardi et al., 2010; T. K Mackey, 2018; Sugiura, 2018). In particular, legal online pharmacies have grown, broadening their supplies to performance-enhancing drugs, prescription drugs and more broadly medicine (European Monitoring Centre for Drugs and Drug Addiction, 2016). This mode of business offers convenience and home delivery to patients. Legal online pharmacies comply with national and international regulations and standards thus guaranteeing the quality of the product. Controlled medicine requires a valid prescription from the patient (European Monitoring Centre for Drugs and Drug Addiction, 2016; Levaggi et al., 2009). In recent years, there has been a growing number of sales of prescription drugs and medicine on illicit online pharmacies (Cohen, Collins, Darkes, \& Gwartney, 2007; Koenraadt \& van de Ven, 2018; Lavorgna, 2015). Illicit websites have appeared through which prescription substances can be purchased without any prescriptions, at a lower price and without having to discuss the medical problem (if any) with a doctor (Di Nicola et al., 2015; Forman, Woody, McLellan, \& Lynch, 2006; Koenraadt \& van de Ven, 2018). These sites are not registered with a recognised accreditation system and represent an issue for health care as substances for sale are not regulated, the quality of the product is not guaranteed, and the products offered for sale might have been diverted from the licit market (Gelatti et al., 2013; Koenraadt \& van de Ven, 2018; Sugiura, 2018). Mandated by the Centre for Safe Internet Pharmacies (CSIP), a study conducted in 2016 (LegitScript, 2016) showed that approximately 30,000 pharmacies hostnames were found online, potentially linked to 2000-3500 merchants. Among these, 96\% operated illegally, 10\% sold controlled substances (e.g. oxycodone, alprazolam, etc.) and 5\% sold steroids (T. K. Mackey \& Nayyar, 2016). Furthermore, according to the World Health Organisation (WHO), 
around $50 \%$ of medicines sold online from illegal sites are counterfeits (WHO, 2010).

Numerous studies have been conducted to explore the online supply of medicines via online pharmacies, both legal and illegal (for example (Di Nicola et al., 2015; European Monitoring Centre for Drugs and Drug Addiction, 2016; Forman et al., 2006; Gelatti et al., 2013; Koenraadt \& van de Ven, 2018; Levaggi et al., 2009; McC oy et al., 2012; Orsolini, Francesconi, Papanti, Giorgetti, \& Schifano, 2015)). The project 'Fakecare' aimed at developing a more accurate understanding of the online trade of falsified medicine using different approaches (e.g. web survey, virtual ethnography, web content analysis, interviews, judicial cases and honeypot websites) (Di Nicola et al., 2015). The web survey was conducted in seven European Member States, targeting customers or potential customers who purchased medicinal products. An exploratory web content analysis was conducted on both legal and illegal online pharmacies. Their results, combined with several interviews, showed that $16.1 \%$ of the web survey respondents reported buying online. The most popular products reported being bought online were "life-style medicines" (i.e. erectile dysfunction medicine, weight loss medicines, birth control pills or smoking cessation). In 2018, Koenraadt and van de Ven studied the demographic characteristics, methods and preference of Dutch people who purchased prescription drugs through the web (Koenraadt \& van de Ven, 2018). Based on two surveys, they reported that $10.2 \%$ of the Dutch adult population had bought prescription drugs online. According to the study, the main prescription drugs and medicine bought online were analgesic, appetite suppressant, tranquilisers and vasodilator. Cicero et al. (Cicero \& Ellis, 2012) observed that consumers reported purchasing online (on licit online pharmacies) because it appeared to be cheaper than seeing a general practitioner or the dose prescribed was too small. Gelatti et al. (Gelatti et al., 2013) ordered fluoxetine from several websites (none of them officially approved). About $20 \%$ of their purchase resulted in the delivery of the drugs, even without a medical prescription. However, drug quality did not comply with European standards in terms of the presence of impurities, suggesting a risk for the users. McCoy et al. (McCoy et al., 2012) analysed the content of databases and transactional metadata of GlavMed, SpamIt and RX-Promotion pharmaceutical affiliate programs (i.e. affiliate websites that advertise and redirect the client to a main illicit shopping website) (Levchenko et al., 2011). They observed that the market was steadily attracting new customers. Repeat orders by the same customers was also an important part of the system and constituted around one-third of the entire revenue for the two major programs (GlavMed and SpamIt), highlighting clear signs of customer satisfaction. The fact that drugs that have an abuse potential were over-represented (in particular on RX-Promotion) reinforces the hypothesis that abuse may be a driver of demand (McCoy et al., 2012). While GlavMed and SpamIt were located in Russia, the United States dominated the orders (75\%), followed by Canada, Australia and Western European countries. In 2010, Inciardi et al. analysed five different datasets and showed that sourcing prescription drugs on the web was generally rare, particularly among the individual end-users of these drugs (Inciardi et al., 2010). It was, however, stated that although the web might not be a major source for end-users, it may play a role at the dealer level (European Monitoring Centre for Drugs and Drug Addiction, 2016; Inciardi et al., 2010).

Prescription drugs and medicine are also offered for sale on cryptomarkets located on the Darkweb. Cryptomarkets are "a type of website that uses advanced encryption to protect the anonymity of the users" (Martin, 2014b). On these websites, a large range of illicit goods - mainly illicit drugs - are traded while taking advantage of various encryption techniques to obfuscate the participants' identity (Broséus et al., 2016; Demant, Munksgaard, \& Houborg, 2018; Martin, 2014a). They have provided new opportunities and challenges for both health and law enforcement agencies (European Monitoring Centre for Drugs and Drug Addiction, 2016; T. K Mackey, 2018). According to the European Monitoring on Centre for Drugs and Drug Addiction (EMCDDA) (European Monitoring Centre for Drugs and Drug Addiction, 2016), cryptomarkets may become more involved in the supply of prescription drugs in the future. Although illicit drug trafficking on cryptomarkets have been thoroughly studied (see for example (Barratt, Ferris, \& Winstock, 2014; Broséus, Morelato, Tahtouh, \& Roux, 2017; Broséus et al., 2016; Kruithof et al., 2016; Rhumorbarbe, Staehli, Broséus, Rossy, \& Esseiva, 2016; Joe Van Buskirk, Roxburgh, Bruno, \& Burns, 2015; J. Van Buskirk, Roxburgh, et al., 2016)), little research has focused exclusively on the trafficking of prescription drugs and medicine. The Enhancing Police Skills on Novel Psychoactive Substance (EPS NPS) project recently analysed the market of prescription drugs, in particular, benzodiazepines on AlphaBay (Mignone \& Novara, 2017) between 2015 and 2016. According to the results, prescription drugs and benzodiazepines represented almost $15 \%$ of the total drug market (including illicit drugs, steroids, etc.). Regarding benzodiazepines, alprazolam was the most offered for sale on AlphaBay, followed by diazepam. The next types of substances commonly offered on AlphaBay were erectile dysfunction (e.g sildenafil), opioid pain medications (e.g. oxycodone) and hypnotic drugs (e.g. zolpidem). According to their analysis, the United States, the United Kingdom, China and India managed the trafficking of prescription drugs. 
In 2018, Martin et al. (Martin, Cunliffe, Décary-Hétu, \& Aldridge, 2018) investigated the effect of restricting the legal supply of prescription opioids by the US Drug Enforcement Administration in 2014 on the sales of these substances on cryptomarkets in the United States. They observed that this change coincided with a statistically significant increase in the transactions of opioids from the United States on cryptomarkets. More recently, Cunliffe et al. (Cunliffe, Décary-Hêtu, \& Pollak, 2019) investigated the nature of the non-opioid prescription medications on cryptomarkets. They analysed data collected on 31 cryptomarkets between 2013 and 2016 to uncover trends as well as total market activity. They observed that sedatives (tranquilisers) and CNS stimulants (psychostimulants) had the greatest share of sales, but usage and trends varied by location.

Given the limited number of studies that focused on the trafficking of prescription drugs and medicine on cryptomarkets, the aim of this article was to obtain a better understanding of the sales of prescription drugs on cryptomarkets. It was decided to focus on the AlphaBay cryptomarket, a well known and popular cryptomarket at its time of activity (between December 2014 and July 2017). This article complements previous studies (Cunliffe et al., 2019; Martin et al., 2018) and brings further knowledge on the trafficking flows between countries and the sales and revenue of vendors of prescription drugs and medicine on cryptomarkets. Rather than focusing on groupings of substances, it provides a closer

\section{Methodology}

\subsection{Datasets}

\subsubsection{AlphaBay cryptomarket}

This research relied on data extracted from AlphaBay (an active cryptomarket between December 2014 and July 2017) (European Monitoring Centre for Drugs and Drug Addiction and Europol, 2017). Data extraction was conducted using a fitfor-purpose crawler. The global process is described in the following sentences. Only data related to the category "Drugs and chemicals" was extracted (excluding other categories such as weapons, carding and other goods) (see figures 1 and 2). Several robots were designed to crawl the cryptomarket and parse data from the listings and vendors' profile pages. For each crawling session, dozens of TOR circuits were generated, which were used by the crawling robots to travel across the cryptomarket. A task management system was built to assign missions to each robot and control the success of their tasks. This system was set up to increase the quality and completeness of the extracted data.

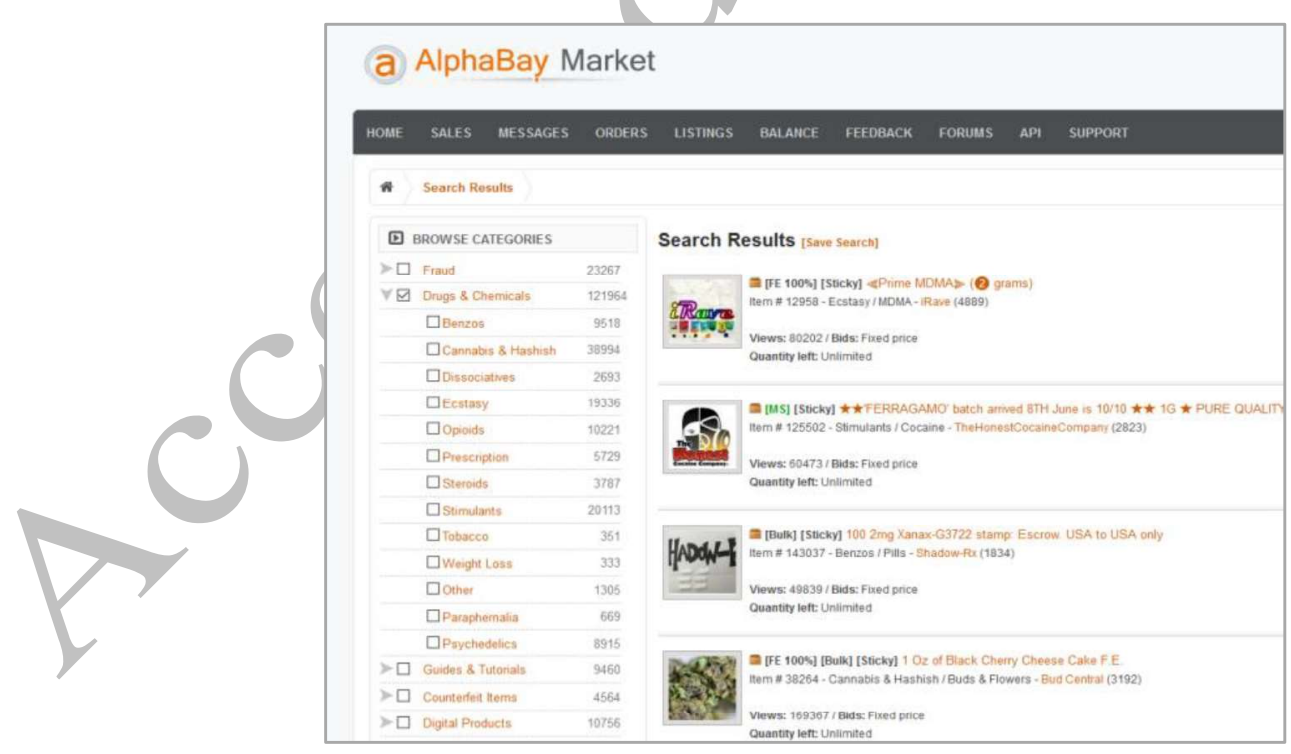

Figure 1. Snapshot of the AlphaBay cryptomarket 
Three crawls were obtained at different times (on February 13th, May 24th and July 4th 2017). The last crawl was conducted a few days before AlphaBay was shut down by a law enforcement operation (European Monitoring Centre for Drugs and Drug Addiction and Europol, 2017). Since listings can be taken down by vendors at any point in time and the dataset is based on three crawls only, there is a possibility that the number of listings captured is under-estimated. However, the number of listings crawled is consistent with another study (Paquet-Clouston, Décary-Hétu, \& Morselli, 2018). Paquet-Clouston et al. (Paquet-Clouston et al., 2018) collected data in September, October, November and December 2015 as well as in January and February 2016. They observed a gradual increase of listings over the six months period, with 25,395 listings in February 2016. Given that our dataset was collected in 2017, a gradual increase of the listings was expected. In July 2017, a total of 31,859 unique sale proposals in the category "drugs and chemicals" were extracted on AlphaBay, in line with the gradual increase of listings observed by Paquet-Clouston et al. (Paquet-Clouston et al., 2018). As three crawls were available, a listing may be represented in one or more crawls (three times maximum). The last crawl of each listing was considered for the analysis to avoid any duplicates and consider each listing as unique. Similar to (Broséus, Morelato, et al., 2017; Broséus, Rhumorbarbe, Morelato, Staehli, \& Rossy, 2017), listings were semi-automatically reclassified based on a list of keywords related to the type of products offered for sale.

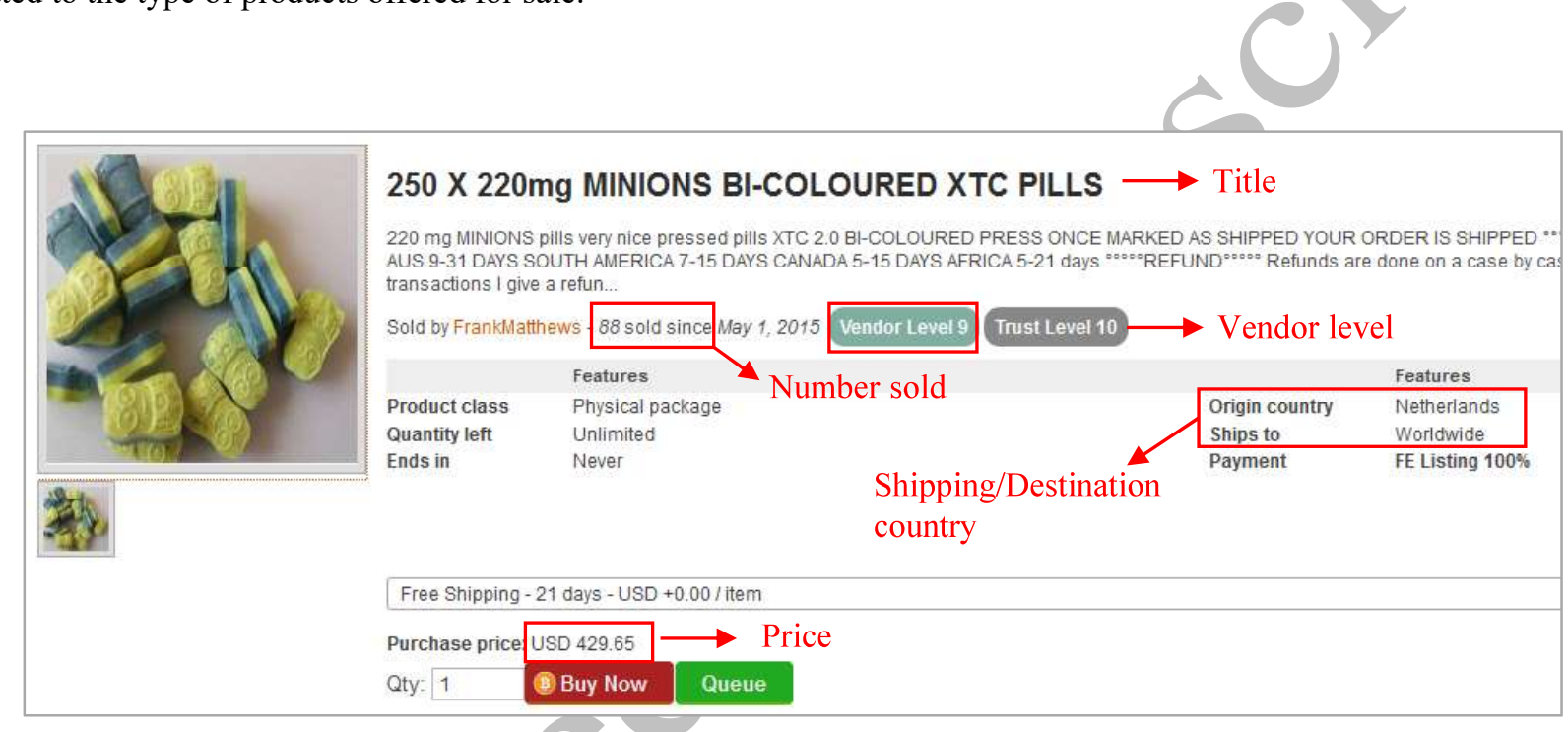

Figure 2. Snapshot of a listing on AlphaBay.

\subsubsection{Choice of substances}

Out of the 31,859 sale proposals, 7,469 listings (23.4\%) offered by 1299 distinct vendors were related to prescription drugs and medicine. In order to cover the most popular substances, the substances accounting for more than $70 \%$ of the total number of listings of prescription drugs and medicine were selected (i.e. twenty-four substances). These substances, as well as their most common brand names, are summarised in Table 1. A brand name might include two active substances. For instance, Adderall ${ }^{\circledR}$ contains Dextroamphetamine and Amphetamine, Suboxone $\AA$ contains a mixture of Buprenorphine and Naloxone, Norco ${ }^{\circledR}$ contains Hydrocodone and Acetaminophen and Percocet ${ }^{\circledR}$ contains Oxycodone and Acetaminophen. Similar to (Cunliffe et al., 2019), diclazepam was also considered in the analysis, although it is not a prescription drug. It was considered as it is a functional analogue of diazepam and is likely to be purchased as a substitute for diazepam (Moosmann, Bisel, \& Auwärter, 2014). Listings offering an illicit drug in combination with the selected substances ( $\mathrm{n}=122$ ) were removed as the price would be inaccurate, resulting in the analysis of 5,439 listings (offered by 1,079 vendors). 
Table 1. Targeted prescription drugs and medicines (active substances and common brand names)

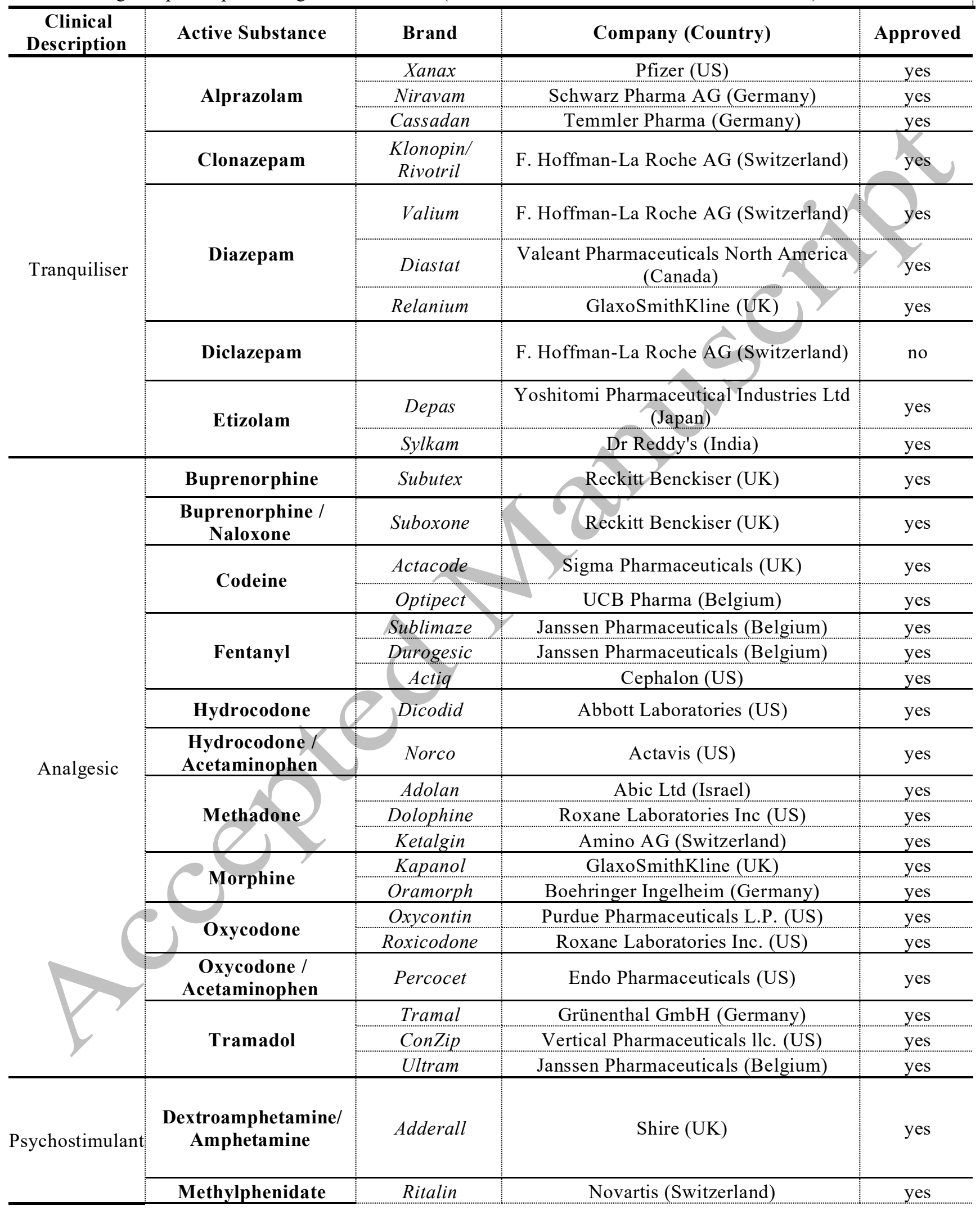




\begin{tabular}{c|c|c|c|c} 
& & Concerta & Janssen Pharmaceuticals (Belgium) & yes \\
\cline { 2 - 5 } & Modafinil & Modiodal & Cephalon (US) & yes \\
\hline \multirow{2}{*}{$\begin{array}{c}\text { Appetite } \\
\text { supressant }\end{array}$} & $\begin{array}{c}\text { 2,4-dinitrophenol } \\
\text { (DNP) }\end{array}$ & & Cephalon (US) & yes \\
\cline { 2 - 5 } & Phentermine & Adipex & no \\
\hline \multirow{3}{*}{\begin{tabular}{c} 
Pasodilator \\
\cline { 2 - 5 }
\end{tabular}} & Sildenafil & Viagra & Gate (US) & yes \\
\cline { 2 - 5 } & Tadalafil & Revatio & Pfizer (US) & yes \\
\hline \multirow{2}{*}{ Hypnotic } & Zolpidis & Pfizer (US) & yes \\
\hline
\end{tabular}

\subsection{Data analysis}

\subsubsection{Volumes and revenues}

For each substance selected, the number of unique listings and the number of vendors (distinguished by their usernames) were calculated to evaluate the volume of prescription drugs and medicine. Additionally, the number and type of substances sold by each vendor were also calculated to describe the extent of their share in the market. In contrast to other cryptomarkets and previous studies (Cunliffe et al., 2019; Soska \& Christin, 2015), the number of sales was directly available on AlphaBay (see Figure 2), so feedback was not used as a proxy of the number of sales.

The price of the targeted substances was extracted from the listings' title. Revenues were then estimated by multiplying the number of sales by the price in US dollar (USD). Although the price may be altered over time and listings may change, it was assumed that all sales were made at the price listed at the time data were extracted. In addition, it is common practice on cryptomarkets to assign high prices to listings that are temporarily in shortage or unavailable, as the vendor does not want to lose visibility by removing their listing (Bakken, Moeller, \& Sandberg, 2017; Soska \& Christin, 2015). These prices also known as "holding prices" - were considered as outliers and therefore removed from the revenue analysis similar to previous studies (Broséus, Morelato, et al., 2017; Décary-Hétu, Paquet-Clouston, \& Aldridge, 2016; Soska \& Christin, 2015). The listings with prices above $10^{\prime} 000$ were manually checked (based on the ratio of the mass sold and the price) and any listings considered inconsistent in terms of mass and price were also filtered out $(\mathrm{n}=370)$ (Aldridge \& Décary-Hétu, 2016).

\subsubsection{Geographical analysis}

Shipping countries and destinations were analysed to evaluate the trafficking routes. Although it is not possible to verify the accuracy of the origin, we based our analysis on the assumption that the shipping country is the country of operation of the vendor, which is consistent with previous approaches (Aldridge \& Décary-Hétu, 2016; J. Van Buskirk, Naicker, Roxburgh, Bruno, \& Burns, 2016). To obtain an indication of the proportion of listings, sales or vendors per inhabitants of a particular country, the values were normalised to 100,000 inhabitants (source: 2017 data from the UNODC2)

The revenue per country of origin and per vendor was also compared to identify the most prominent countries and vendors in the trade of prescription drugs. When a vendor indicated only one country, it was assumed that all products were shipped from that country. When a vendor indicated a particular country as well as "Worldwide", "Worldwide" was not taken into account. If a vendor was shipping from two or more countries, the country of the seller was labelled as "unknown".

\subsubsection{Vendors' profile}

In order to gain more information about prolific vendors, a qualitative analysis was conducted on the first twenty most active vendors (in terms of number of sales over the entire period studied). Any information about the number of vendors involved, the language used, the shipping countries (and final destination(s)) and the supplier were highlighted and aggregated. The vendors' pseudonyms were anonymised, and their statements paraphrased to avoid giving away any identifying information 
that could contradict ethical and privacy recommendations (Martin \& Christin, 2016).

\section{Results and discussion}

\subsection{Size and nature of the market}

Listings of prescription drugs and medicine represented $23.4 \%$ of the total number of sale proposals in the category "drugs and chemicals". This percentage is in line with the results of Kruithof et al. (Kruithof et al., 2016) who analysed data from eight cryptomarkets (AlphaBay included): $24 \%$ of drug listings were reported to be prescription drugs and medicine. The targeted substances (see table 1) covered 5,439 listings, which represented more than $70 \%$ of the prescription drugs and medicine's listings and were offered by 1,079 distinct vendors. Alprazolam, oxycodone and the mixture dextroamphetamine/amphetamine (Adderall $\mathbb{R}$ ) accounted for the majority of listings and were offered by the majority of vendors while alprazolam, diazepam and oxycodone accounted for the majority of sales (see Figure 3 ).
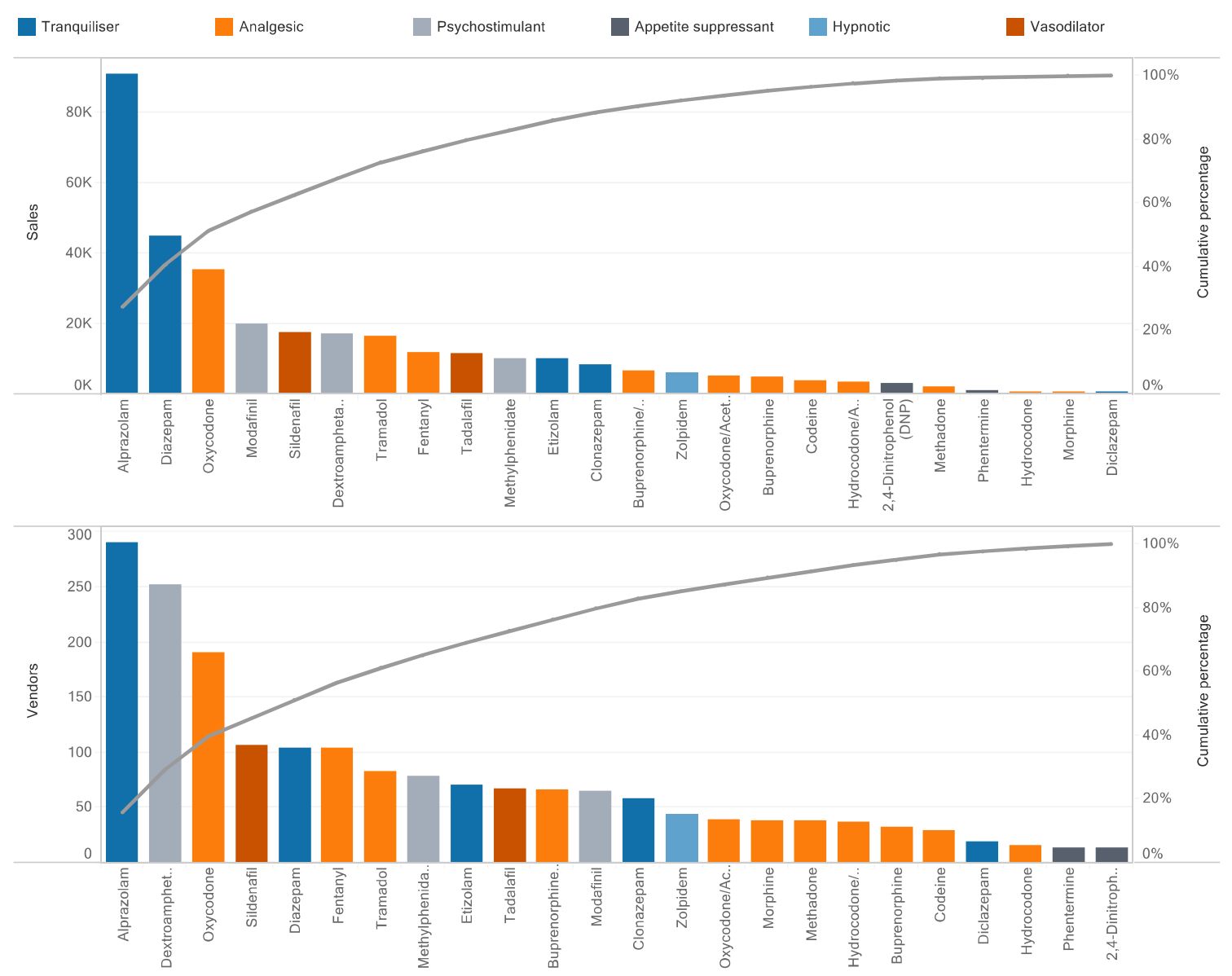

Figure 3. Proportions of sales and vendors offering the different active substances ( $\mathrm{n}=5,439$ listings and 1,079 vendors). The grey line represents the cumulative percentage of vendors and sales for each type of products offered.

Tranquilisers (mainly benzodiazepines) and analgesic (mainly opioid pain medications) accounted for approximately $70 \%$ of the prescription drug listings targeted in this study (respectively 34.9\% and 33.2\%). According to Olfson et al. (Olfson, King, \& Schoenbaum, 2015) and the UNODC (United Nations Office on Drugs and Crime, 2018), benzodiazepines are one of the most commonly prescribed drugs in developed countries. The UNODC reported that opioid pain medications (e.g. hydrocodone, oxycodone, fentanyl), central nervous system depressants (e.g. barbiturates and benzodiazepines) and central nervous system stimulants (e.g. dextroamphetamine, methylphenidate) were the most common types of prescription 
medication used in a non-medical context (United Nations Office on Drugs and Crime, 2011, 2018). In our study, alprazolam was the most offered for sale $(20.6 \%)$ as well as the most sold substance $\left(27.2 \%\right.$ of sales). Most commonly known as Xanax ${ }^{\circledR}$ (by Pfizer), it is a minor tranquiliser with a benzodiazepine core and often prescribed for anxiety and panic disorder. In the United States, alprazolam is among the prescription drugs most commonly diverted from the licit market (United Nations Office on Drugs and Crime, September 2017). There thus seems to be similar trends between prescription drugs commonly abused and diverted from the licit market and their sales on cryptomarkets.

Table 2. Revenue and its percentage per type of substances.

\begin{tabular}{|c|c|c|c|}
\hline Clinical Description & Active Substance & Revenue [USD] & Revenue [\%] \\
\hline \multirow{6}{*}{ Tranquiliser } & Alprazolam & $38,368,717$ & 58.3 \\
\hline & Diazepam & $1,939,202$ & 2.9 \\
\hline & Etizolam & 587,771 & \\
\hline & Clonazepam & 659,488 & 1.0 \\
\hline & Diclazepam & 51,255 & 0.1 \\
\hline & Total & $41,606,433$ & 63.2 \\
\hline \multirow{12}{*}{ Analgesic } & Oxycodone & $9,649,604$ & 14.7 \\
\hline & Fentanyl & $3,771,940$ & 5.7 \\
\hline & Tramadol & & 1.0 \\
\hline & Buprenorphine/Naloxone & 752,555 & 1.1 \\
\hline & Hydrocodone/Acetaminophen & $1,007,753$ & 1.5 \\
\hline & Methadone & 250,780 & 0.4 \\
\hline & Oxycodone/Acetaminophen & $1,403,979$ & 2.1 \\
\hline & Morphine & 46,230 & 0.1 \\
\hline & Buprenorphin & 302,617 & 0.5 \\
\hline & Codeine & 124,003 & 0.2 \\
\hline & Hydrocodone & 66,660 & 0.1 \\
\hline & Total & $18,020,300$ & 27.4 \\
\hline \multirow{4}{*}{ Psychostimulant } & Dextroamphetamine/Amphetamine & $3,392,000$ & 5.2 \\
\hline & Modafinil & 873,227 & 1.3 \\
\hline & Methylphenidate & 619,987 & 0.9 \\
\hline & Total & $4,885,214$ & 7.4 \\
\hline \multirow{3}{*}{ Vasodilator } & Sildenafil & 371,405 & 0.6 \\
\hline & Tadalafil & 344,355 & 0.5 \\
\hline & Total & 715,760 & 1.1 \\
\hline \multirow{3}{*}{ Appetite suppressant } & 2,4-Dinitrophenol (DNP) & 122,307 & 0.2 \\
\hline & Phentermine & 72,931 & 0.1 \\
\hline & Total & 195,238 & 0.3 \\
\hline Hypnotic & Zolpidem & 384,658 & 0.6 \\
\hline Total & & $65,807,605$ & 100 \\
\hline
\end{tabular}




\subsection{Revenue of prescription drugs vendors}

Based on unique sale proposals, the revenue of the targeted prescription drugs and medicine on AlphaBay was estimated to be over 65 million USD, a very small market in comparison to the worldwide legal pharmaceutical market's estimate of 1.3 trillion USD in 2020 or the global counterfeit drug market's estimate which ranges from 75 to 200 billion USD 1 (International trade administration, 2016). However, it is important to keep in mind that our estimate may be an underestimation as the price may have changed over time and holding prices were removed even though the listings may have been sold before running out of stock. According to Table 2, the sales of alprazolam (i.e. Xanax ${ }^{\circledR}$ ) accounted for almost $60 \%$ of the total revenue, a large percentage in comparison to the percentage of listings and vendors, respectively. Interestingly, a number of alprazolam listings included very large quantity $(1 \mathrm{~kg})$ of the substance and were sold up to 25 times. According to the Enhancing Police Skills on NPS project (Mignone \& Novara, 2017), benzodiazepines (e.g. alprazolam) are the most prescribed drugs and most sold in the physical world too. They are also commonly misused by polydrug users. Oxycodone is commonly used in combination with alprazolam for recreational purposes. These findings are worrying as it was shown that the non-medical use of benzodiazepines in combination with prescription opioids had been involved in a number of overdoses and acute intoxication (United Nations Office on Drugs and Crime, September 2017).

\subsection{Geographical analysis}

Figure 4 represents the number of listings, sales and vendors per country and per 100,000 inhabitants. Only the first 10 countries contributing to the majority of sales per 100,000 inhabitants are represented. English-speaking countries, as well as European countries, seem to dominate the market (i.e. the United States, the United Kingdom, Australia, Canada and Germany) for both listings, sales and vendors. These findings were also noted for illicit drugs, where the trafficking was dominated by English-speaking and Western European countries (Broséus, Rhumorbarbe, et al., 2017; Cunliffe et al., 2019; Kruithof et al., 2016; J. Van Buskirk, Naicker, et al., 2016). This may, however, only reflects countries' Internet access and digital literacy (Büchi, Just, \& Latzer, 2016; Demant, Aldridge, Décary-Hétu, \& Munksgaard, 2018).

Australia stands out for all three parameters (number of listings, vendors and sales). Interestingly, a limited number of vendors from the United Kingdom offer a few listings in comparison to the number of sales they generate (country with the highest number of sales). Another interesting country is Denmark, which is ranked fifth in the number of sales per 100,000 inhabitants. Denmark is characterised by a small number of vendors compared to the number of listings and sales. This may suggest that only a few vendors managed most of the listings coming from this country and the number of sales from this country is relatively high in comparison to its population. It is difficult to explain whether the predominance of these countries on cryptomarkets is due to their role in the trafficking of prescription drugs and medicine or to their access to the Internet and marketplaces located on the Darkweb. For instance, certain countries like China have introduced censorship and content filtering to control Internet trafficking, and access to specific sites is very complex. This may explain their minor presence on these marketplaces (Ensafi, Winter, Mueen, \& Crandall, 2015).

Figure 5 shows the directional flows (origin and destination(s)) of prescription drugs and medicine for the most frequent combinations of origin/destination countries3. This representation reveals the extent of the trafficking for the main countries involved in the trafficking of prescription drugs and medicine as well as the nature of the trafficking (domestic vs international).

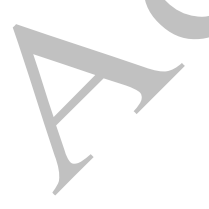

1 It is not clear how this global estimate was calculated. 


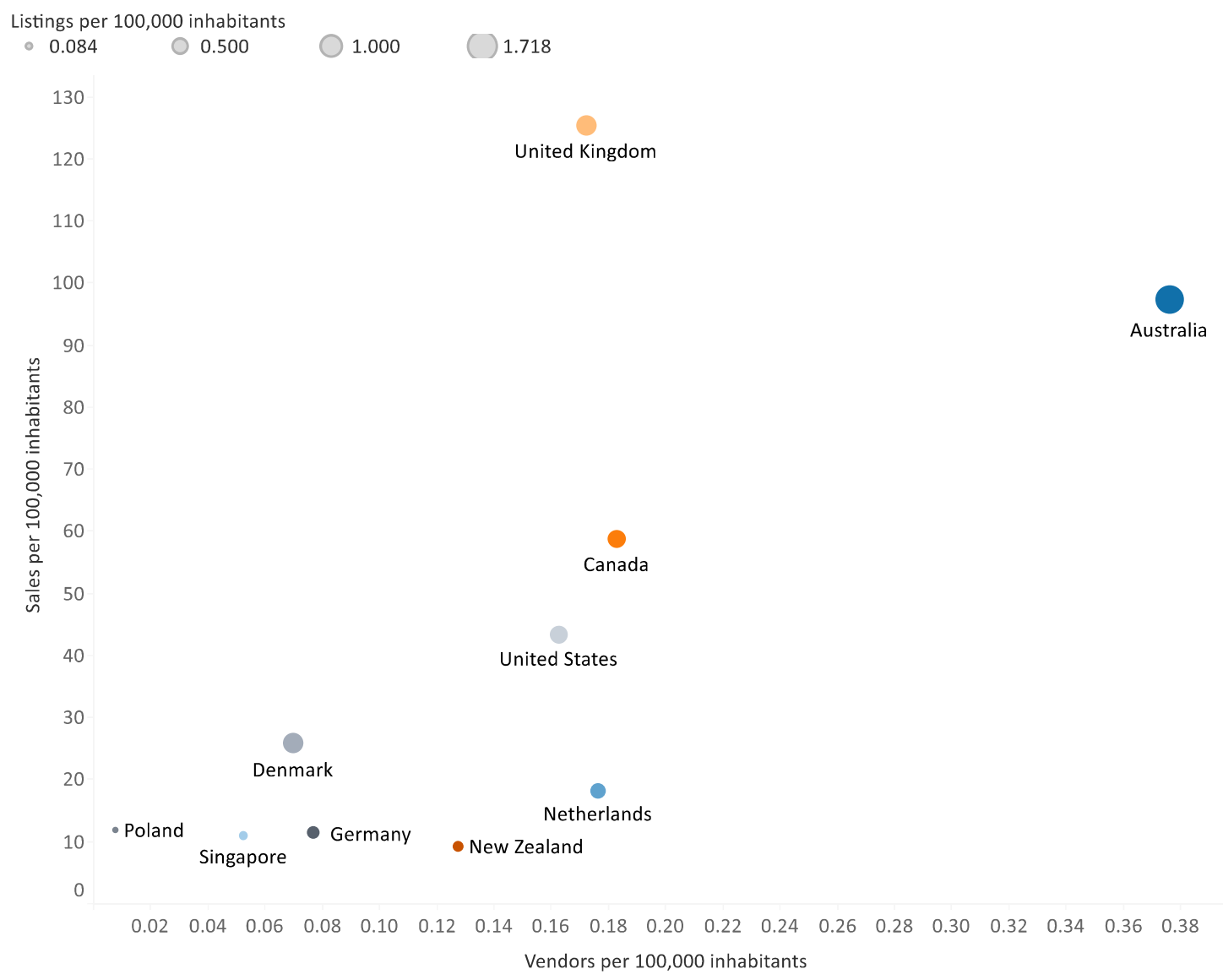

Figure 4. Number of sales (y-axis) per vendors ( $\mathrm{x}$-axis) per shipping countries and per 100,000 inhabitants $(n=5,439$ listings and 1,079 vendors). The number of listings per 100,000 is represented by the size of the dots. Only the first 10 countries contributing to the majority of sales per 100,000 inhabitants are represented.

Although Europe and North America are not countries, vendors can choose these regions as a destination. They might be willing to ship their goods to all European countries or to all countries in North America while avoiding the rest of the world to prevent interception at borders or expensive shipping fees. The market is domestic in Australia (i.e. Australian vendors offer prescription drugs to Australian customers) and mainly domestic in the United States. In contrast, the Netherlands and Germany principally export internationally (to "Worldwide" or Europe). Similar results were observed for illicit drug trafficking (Broséus, Morelato, et al., 2017; Broséus, Rhumorbarbe, et al., 2017). For example, the United States and Australia were shown to offer their substances domestically, while the Netherlands mainly offered internationally. The geographical isolation, domestic production, higher prices, population prevalence, legal context and the risk associated with selling internationally were among the factors raised to explain domestic trafficking (Broséus, Morelato, et al., 2017; J. Van Buskirk, Naicker, et al., 2016).

Only looking at the trafficking flows is not sufficient as vendors from a particular country could sell a limited number of goods in large quantity and at a high price. In contrast to the United States, Canada and China only sold a limited number of goods, but their revenue appeared to be high, an indication of business to business sales and possibly those being origin countries (see Table 3). This was also observed in previous studies which indicated that vendors from these countries were able to source large quantities of products, from either illicit production (e.g. China) or through online pharmacies and other 
wholesale distribution sources (e.g. Canada) (Aldridge \& Décary-Hétu, 2014; Cunliffe et al., 2019). According to Table 3, English-speaking countries (i.e. the United States, Canada, Australia and the United Kingdom) account for approximately $84.1 \%$ of the total revenue. It may reflect the countries' Internet penetration rates 4 or the fact that non-English speakers may be more likely to go to national non-English language markets (European Monitoring Centre for Drugs and Drug Addiction and Europol, 2017).
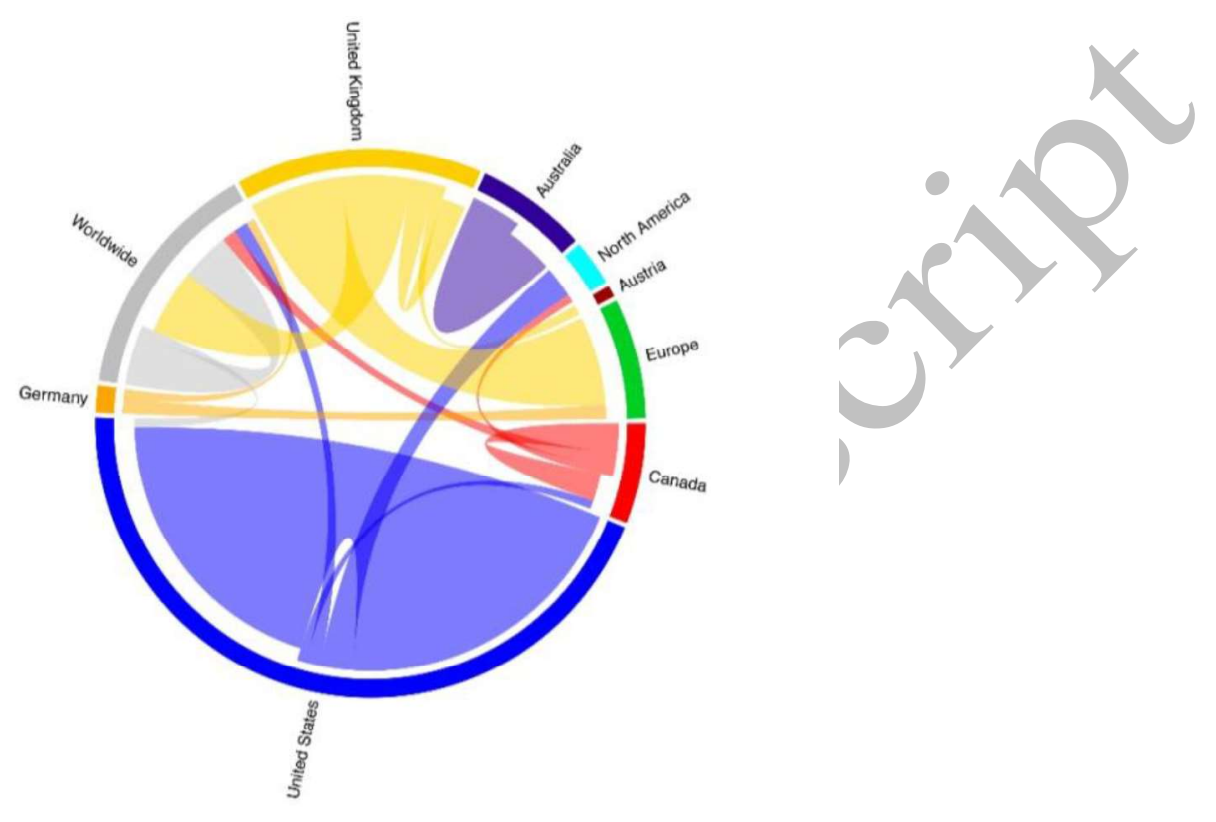

Figure 5. Prescription drugs trafficking flows (based on the number sold). Only combination of origin/destination countries having a frequency of listings of at least $1 \%$ in relation to the total number of sales were considered (i.e. combinations with number of sales above 3354).

Without considering "Worldwide", North America largely dominates the market (i.e. 76.3\% of the total revenue). Alternatively, the issue related to prescription drugs and in particular prescription opioids use in the United States in comparison to other countries has been raised in recent years and several reasons have been hypothesised, such as less severe regulatory systems operating in the United States than in other countries, a change of legislation and the different prescription and dispensing practices (European Monitoring Centre for Drugs and Drug Addiction, 2016; Fischer, Keates, Bühringer, Reimer, \& Rehm, 2014). These reasons could explain the predominance of North America in these markets. Interestingly, China's revenue is high in contrast to the number of vendors stating to operate from this country (results not shown) as well as the number of sales generated. Furthermore, they are willing to take the risk to ship their substances "Worldwide" (see Figure 2). This reveals a feature in their market structure, in which a few vendors manage all listings which are mostly of large quantity. This was also noted by Broséus et al. in 2017 (Broséus, Rhumorbarbe, et al., 2017).

Table 3. Revenue and its percentage per shipping country ( $n=65,807,605$ USD). Only countries whose revenues are over 500,000 USD between December 2014 and July 2017 are presented.

\begin{tabular}{|c|c|c|c|}
\hline Country & Revenue [USD] & Revenue [\%] & Number sold \\
\hline United States & $28,820,429$ & 43.8 & 133,522 \\
\hline Canada & $21,422,994$ & 32.6 & 19,563 \\
\hline Worldwide & $6,965,332$ & 10.6 & 30,833 \\
\hline United Kingdom & $3,213,965$ & 4.9 & 71,999 \\
\hline China & $1,999,814$ & 3.0 & 1,072 \\
\hline Australia & $1,909,306$ & 2.9 & 21,805 \\
\hline Germany & 545,485 & 0.8 & 8,778 \\
\hline
\end{tabular}




\subsection{Analysis of the main vendors}

\subsubsection{Type of goods offered for sale}

Figure 6 represents the type of substances sold by the twenty most prolific vendors in terms of the number of sales. Most vendors seem to diversify their sales as thirteen out of twenty offer a variety of prescription drugs and medicine. Eleven of them sell alprazolam. Usually, vendors offering sildenafil also offer tadalafil. This seems to differ from the research on illicit drugs that was conducted by Paquet-Clouston et al. (Paquet-Clouston et al., 2018) who showed that product diversification is low. However, the categories used in their research were broader and included illicit drugs (e.g. ecstasy, cannabis, psychedelics, stimulants, prescriptions, opioids and others), and their analysis was conducted on all the vendors. Access to different types of illicit drugs is more complicated. It is thus difficult to directly compare the findings.

\subsubsection{Vendors' profile}

The length and content of the vendors' description profile seem to have no influence on their popularity, as half of them provided a short description (i.e. eight vendors) or no description (i.e. four vendors). The popularity of certain vendors may be explained by their presence on different cryptomarkets. Indeed, $41.6 \%$ of vendors stated to be present on other cryptomarkets. Furthermore, vendors may be present on both the web and the dark web. It is not uncommon that vendors mention a website in their description profile. In 2015, Soska and Christin conducted a two-year study on multiple cryptomarkets and observed that a large proportion of vendors sold on multiple marketplaces at the same time (Soska \& Christin, 2015). Another study focusing on the Canadian market also showed that some vendors are present on several cryptomarkets to increase their visibility and their profit (Broséus et al., 2016).

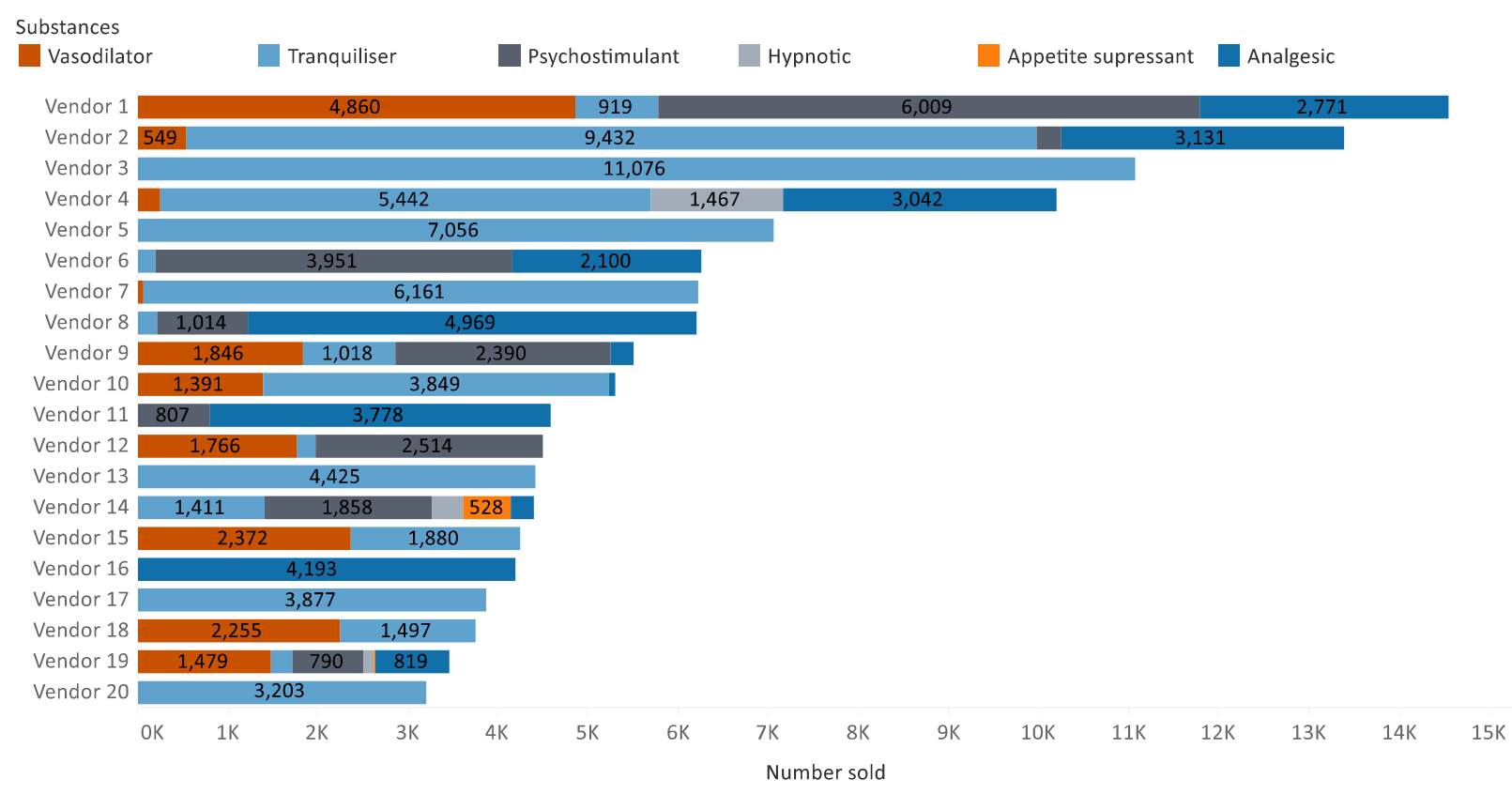

Figure 6. Prescription drugs and medicine sold by the first twenty most active vendors.

The origin of the products they offer for sale was difficult to establish as the vendors did not provide complete information about their suppliers. Almost 50\% of them did not mention any suppliers. This might be for safety reason. Vendors want to provide sufficient information to attract customers while maintaining their anonymity. Pharmacists and doctors may play a role as suppliers, knowingly or unknowingly, as some vendors reported the use of real prescriptions for their supply. However, pharmacists and doctors may be unaware as many methods of diversion exist such as "Doctor shopping" (obtaining 
prescription drugs from different doctors, a US phenomenon), sourcing drugs through someone else's legitimate prescription or even theft (Han, Jones, Blanco, \& Compton, 2017; United Nations Office on Drugs and Crime, September 2017). Five vendors stated that they produced their own products. Bakken et al, (Bakken et al., 2017) stated that direct contact with the manufacturer could mean that consumers purchasing from these vendors could receive more information about the drugs they are using which could, in turn, reduce the harm of drug use (Barratt et al., 2014; Van Hout \& Bingham, 2013).

Finally, products other than prescription drugs and medicine were also offered by $25 \%$ of vendors. A diversification of the market might attract more buyers. Some vendors offered illicit drugs, such as LSD and cannabis in combination with prescription drugs. The combination of illicit drugs and prescription drugs is commonly used for recreational purpose (Kelly, Wells, Pawson, LeClair, \& Parsons, 2014; Mignone \& Novara, 2017).

3.4.3 Vendors' revenue

Table 4 summarises the revenue of vendors who have made over five hundred thousand USD since the creation of AlphaBay, representing $66.4 \%$ of the total revenue of prescription drugs. Vendors from the United States were the most prolific vendors of prescription drugs on AlphaBay. The vendors with the highest revenue also sold prescription drugs in large quantity. Soska and Christin found that around $70 \%$ of vendors sold less than 1000 USD worth of products and only $2 \%$ of vendors sold more than 100,000 USD worth of products (Soska \& Christin, 2015). They thus seem to have access to a large quantity of these substances. Interestingly, the majority of sales from Vendor 24 are quantities of fentanyl between $0.05 \mathrm{~g}$ to $5 \mathrm{~g}$.

Table 4. Revenue and percentage of vendors whose revenues are over 500,000 USD.

\begin{tabular}{|c|c|c|c|c|c|}
\hline Vendor & Ship from & Revenue [USD] & Revenue [\%] & Vendor level & $\begin{array}{c}\text { Number of } \\
\text { people involved }\end{array}$ \\
\hline Vendor 5 & Canada & $17,149,200$ & 26.1 & 9 & More than one \\
\hline Vendor 20 & Canada & $4,934,730$ & & 10 & More than one \\
\hline Vendor 6 & United States & $3,685,980$ & & 10 & More than one \\
\hline Vendor 21 & United States & $3,160,727$ & 4.8 & 10 & More than one \\
\hline Vendor 11 & United States & $2,493,450$ & 3.8 & 10 & More than one \\
\hline Vendor 22 & United States & $2,028,800$ & 3.2 & 7 & More than one \\
\hline Vendor 23 & United States & $1,852,200$ & 2.8 & 9 & One person \\
\hline Vendor 24 & United States & $1,525,570$ & 2.3 & 8 & One person \\
\hline Vendor 2 & United States & $1,434,855$ & 2.2 & 10 & Unknown \\
\hline Vendor 25 & United States & $1,189,500$ & 1.8 & 8 & More than one \\
\hline Vendor 26 & & 998,678 & 1.5 & 9 & More than one \\
\hline Vendor 27 & China & 726,435 & 1.1 & 8 & More than one \\
\hline Vendor 28 & United States & 649,050 & 1.0 & 9 & One person \\
\hline Vendor 29 & United States & 618,905 & 0.9 & 8 & One person \\
\hline Vendor 30 & United States & 566,040 & 0.9 & 8 & More than one \\
\hline Vendor 1 & Germany & 504,928 & 0.8 & 8 & More than one \\
\hline Total & & $43,726,048$ & 66.4 & & \\
\hline
\end{tabular}

However, they sold 15 times a quantity of 500g costing 75,000 USD. Even though this price is very high, it cannot be considered as a holding price due to the quantity being offered. It appears that this vendor has access to a large quantity of fentanyl. Demant et al. (Demant, Munksgaard, et al., 2018) studied the reasons why buyers purchase illicit drugs on cryptomarkets. According to the results, they also observed that vendors from Silk Road 2 and Agora selling a high quantity of products generated the highest revenue. A possible hypothesis could be their involvement at a high level in the distribution chain, supplying substances for distribution rather than consumption. As a consequence, cryptomarkets may also be a 
business-to-business market, which was also noted in (Aldridge \& Décary-Hétu, 2014; Bakken et al., 2017; Cunliffe et al., 2019). Paquet-Clouston et al. showed that only a small portion of vendors succeed in generating regular sales while the majority of vendors seems to be spectators with a limited number of sales (Paquet-Clouston et al., 2018). They also showed that a high number of start-up entities compete only at minimal performance levels, and there are only a few vendors that achieve some level of establishment. The review of the top five vendor's profile that generated the highest revenue highlighted that English was the language used in all profile description. Vendor's levels were reported5. The vendor level is a number from 1-10, and is allocated to each respective vendor. It is based on a combination of the number of sales, vendor revenue and feedback. As observed in Table 4, vendors who generated large revenues also had a high reputation level. It was shown that consumers are willing to pay higher prices for goods sold by reputable online vendors compared with goods sold by unrated vendors (Paquet-Clouston et al., 2018; Smith \& Brynjolfsson, 2001).

\section{General discussion and conclusions}

This study investigated the trafficking of prescription drugs on the AlphaBay cryptomarket. It was found that analgesic (in particular opioid pain medications) and tranquilisers (in particular benzodiazepines) were the most offered and sold prescription drugs on AlphaBay. The non-medical use of benzodiazepines with opioids has been concerning for control and prevention measures (United Nations Office on Drugs and Crime, September 2017). They represent a significant risk to public health due to their abuse potential, and their use has been involved in a rising number of fatalities in North America and Europe (United Nations Office on Drugs and Crime, September 2017). Alprazolam was found to be the most offered and sold prescription drug on this cryptomarket. In comparison to other benzodiazepines, alprazolam has a high misuse liability and its consumption results in more severe withdrawal syndrome (Ait-Daoud, Hamby, Sharma, \& Blevins, 2018). In the United States, alprazolam is considered to be amongst the three main prescription drugs that are diverted from the licit market which could explain its high availability on this cryptomarket (United Nations Office on Drugs and Crime, September 2017). It has also received increasing media coverage due to its alleged recent normalisation in Hip Hop culture in the United States and its links to the death of numerous famous artists (Beaumont-Thomas, 2017; Cunliffe et al., 2019). In addition, there have also been recent reports of pills sold on cryptomarkets as "Xanax" that contained other benzodiazepines (International Energy Control, 2019).

North America (the United States and Canada) seems to play a major role in the sale of prescription drugs and medicine. In both the United States and Canada, a large proportion of prescription opioid harms have been associated with oxycodone formulations (in particular Oxycontin) (Fischer et al., 2014). The problem of prescription opioid is particularly important in North America, and the extent of this phenomenon has not registered anywhere else in the world. The North American trend that we observe on cryptomarket could be due to the demand and offer. It was estimated that about $80 \%$ of all prescription opioids formulations in Canada are dispensed in the community or through community pharmacies with no post-dispensing control mechanisms in place. This would allow an easy diversion of these substances. Furthermore, medical prescription opioid use seems to be much higher in Canada than it is in any other countries. Access control and dispensing modalities thus seem to differ between North America and Europe. There is also a higher reliance on treating illness by prescribing drugs in North America (Fischer et al., 2014). As a consequence, this could also be a reason as to why North America is over-represented in the trafficking of prescription drugs and medicine on AlphaBay.

In regard to vendors, the majority seems to diversify their listings of prescription drugs and medicine, and the most prolific vendors seem to have access to large quantities of the substances offered. Although Paquet-Clouston et al. showed that vendors are much more specialised than diversified, it is difficult to compare our findings with theirs as their drug categories were larger than ours (ecstasy, cannabis, psychedelics, stimulants, prescriptions, opioids and others) (Paquet-Clouston et al., 2018). With relatively low risk in comparison to the high profits that prescription drugs and medicine can make, it is not surprising that criminals have a vested interest in this trade (O'Hagan \& Garlington, 2018). Perhaps, law enforcement agencies should place greater emphasis on targeting the most prolific vendors, rather than shutting down specific cryptomarkets. Décary-Hétu et al. reported that 'Operation Onymous' directed at cryptomarkets Cloud Nine, Hydra and SR2, had deterrent effects in the short-term and showed recovery of vendors and sales on existing and/or novel cryptomarkets following a one-two month period (Décary-Hétu \& Giommoni, 2017). Therefore, the re-emergence of cryptomarkets is recurring over time, while the return of vendors following police crackdowns may not be so likely due to fears of being continually monitored by law enforcement and loss of reputation. Furthermore, according to Paquet-Clouston et al. (PaquetClouston et al., 2018), only a few vendors manage to conduct constant sales over time. Given the large proportion of sales made by a few vendors, it is likely that a large number of customers are also concentrated around these vendors (Felson \& Clarke, 1998).

Although prescription drugs require a valid prescription to be purchased, they are not illegal, and one may ask themselves why are people using cryptomarkets to purchase licit commodities? Several reasons may be raised, such as the non-medical 
use of these drugs, the addictive potential of certain substances (e.g. tramadol, oxycodone), the opportunity given by cryptomarkets (i.e. access to a large number of illegal substances as well as prescription medicine), difficulty to obtain a prescription, lower price, quantity consumed larger than the prescribed dose, anonymity, embarrassment and speed of delivery (Barratt et al., 2014; European Monitoring Centre for Drugs and Drug Addiction and Europol, 2017; United Nations Office on Drugs and Crime, 2018). Furthermore, illegal online activities lead to a decline in the traditional hierarchical distribution chain and an expansion of more flexible and informal criminal networks, which might attract consumers (Di Nicola et al., 2015). Whatever the reasons are, this market seems to be quite small. According to (Abouchedid, Gilks, Dargan, Archer, \& Wood, 2018), there has been an increase of websites selling non-registered benzodiazepines drug (i.e. diclazepam, flubromazepam and pyrazolam) between 2014 and 2016 in the UK/Europe. They reported that the most prominent themes regarding the motivations behind the use of these substances were the treatment of anxiety, sedation/sleep aid, to avoid benzodiazepines withdrawals and "come down" after the use of stimulants such as amphetamines or cocaine. There seems to be a difference between substances purchased through online pharmacies (both legal and illegal) and through cryptomarkets. Indeed, according to the FakeCare project (Di Nicola et al., 2015), life-style drugs and performance enhancing drugs are often sought on the Web while recreation drugs or prescription drugs such as benzodiazepines and opioids seem to be mainly purchased on the DarkWeb. This was confirmed in our study and has also been raised in (Cunliffe et al., 2019).

\section{References}

Abouchedid, R., Gilks, T., Dargan, P. I., Archer, J. R. H., \& Wood, D. M. (2018). Assessment of the Availability, Cost, and Motivations for Use over Time of the New Psychoactive Substances-Benzodiazepines Diclazepam, Flubromazepam, and Pyrazolam-in the UK. J Med Toxicol, 14(2), 134-143. doi:10.1007/s13181-018-0659-3

Ait-Daoud, N., Hamby, A. S., Sharma, S., \& Blevins, D. (2018). A Review of Alprazolam Use, Misuse, and Withdrawal. Journal of Addiction Medicine, 12(1), 4-10. doi:10.1097/ADM.0000000000000350

Aldridge, J., \& Décary-Hétu, D. (2014). Not an 'Ebay for Drugs': The Cryptomarket 'Silk Road' as a Paradigm Shifting Criminal Innovation. doi: $10.2139 /$ ssrn. 2436643

Aldridge, J., \& Décary-Hétu, D. (2016). Hidden wholesale: The drug diffusing capacity of online drug cryptomarkets. International Journal of Drug Policy, 35, 7-15. doi:10.1016/j.drugpo.2016.04.020

Bakken, S. A., Moeller, K., \& Sandberg, S. (2017). Coordination problems in cryptomarkets: Changes in cooperation, competition and valuation. European Journal of Criminology, 1-19. doi:10.1177/1477370817749177

Barratt, M. J., Ferris, J. A., \& Winstock, A. R. (2014). Use of Silk Road, the online drug marketplace, in the United Kingdom, Australia and the United States. Addiction, 109(5), 774-783. doi:10.1111/add.12470

Beaumont-Thomas, B. (2017). The death of Lil Peep: How the US prescription drug epidemic is changing hip-hop. The Guardian. Retrieved from https://www.theguardian.com/music/2017/nov/16/death-lil-peep-us-prescription-drugsepidemic-hip-hop-rapper

Broséus, J., Morelato, M., Tahtouh, M., \& Roux, C. (2017). Forensic drug intelligence and the rise of cryptomarkets. Part I: Studying the Australian virtual market. Forensic Science International, 279, $288-301$. doi:10.1016/j.forsciint.2017.08.026

Broséus, J., Rhumorbarbe, D., Mireault, C., Ouellette, V., Crispino, F., \& Décary-Hétu, D. (2016). Studying illicit drug trafficking on Darknet markets: Structure and organisation from a Canadian perspective. Forensic Science International, 264, 7-14. doi:10.1016/j.forsciint.2016.02.045

Broséus, J., Rhumorbarbe, D., Morelato, M., Staehli, L., \& Rossy, Q. (2017). A geographical analysis of trafficking on a popular darknet market. Forensic Science International, 277, 88-102. doi:10.1016/j.forsciint.2017.05.021

Büchi, M., Just, N., \& Latzer, M. (2016). Modeling the second-level digital divide: A five-country study of social differences in Internet use. New Media \& Society, 18(11), 2703-2722. doi:10.1177/1461444815604154

Cicero, T. J., \& Ellis, M. S. (2012). Health outcomes in patients using no-prescription online pharmacies to purchase prescription drugs. Journal Of Medical Internet Research, 14(6), e174-e174. doi:10.2196/jmir.2236 
Cohen, J., Collins, R., Darkes, J., \& Gwartney, D. (2007). A league of their own: demographics, motivations and patterns of use of 1,955 male adult non-medical anabolic steroid users in the United States. Journal of the International Society of Sports Nutrition, 4(1), 12. doi:10.1186/1550-2783-4-12

Cunliffe, J., Décary-Hêtu, D., \& Pollak, T. A. (2019). Nonmedical prescription psychiatric drug use and the darknet: A cryptomarket analysis. International Journal of Drug Policy. doi:10.1016/j.drugpo.2019.01.016

Décary-Hétu, D., \& Aldridge, J. (2015). Sifting through the Net: Monitoring of Online Offenders by Researchers. The European Review of Organised Crime, 2(2), 122-141.

Décary-Hétu, D., \& Giommoni, L. (2017). Do police crackdowns disrupt drug cryptomarkets? A longitudinal analysis of the effects of Operation Onymous. Crime, Law and Social Change, 67(1), 55-75. doi:10.1007/s10611-016-9644-4

Décary-Hétu, D., Paquet-Clouston, M., \& Aldridge, J. (2016). Going international? Risk taking by cryptomarket drug vendors. International Journal of Drug Policy, 35, 69-76. doi:10.1016/j.drugpo.2016.06.003

Demant, J., Aldridge, J., Décary-Hétu, D., \& Munksgaard, R. (2018). Going Local on a Global Platform: A Critical Analysis of the Transformative Potential of Cryptomarkets for Organized Illicit Drug Crime. International Criminal Justice Review, 28(3), 255-274. doi:10.1177/1057567718769719

Demant, J., Munksgaard, R., \& Houborg, E. (2018). Personal use, social supply or redistribution? cryptomarket demand on Silk Road 2 and Agora. Trends in Organized Crime, 21(1), 42-61. doi:10.1007/s12117-016-9281-4

Di Nicola, A., Martini, E., Baratto, G., Antonopoulos, G., Boriero, D., Da Col, W., . . Zabyelina, Y. (2015). FAKECARE: Developing expertise against the online trade of fake medicines by producing and disseminating knowledge, counterstrategies and tools across the EU. Retrieved from Trento: http://www.fakecare.com/images/pdf/eCrime_Research_Reports_02.pdf

Ensafi, R., Winter, P., Mueen, A., \& Crandall, J. R. (2015). Analyzing the Great Firewall of China Over Space and Time. Proceedings on Privacy Enhancing Technologies(1), 61-76. doi:10.1515/popets-2015-0005

European Monitoring Centre for Drugs and Drug Addiction. (2016). The internet and drug markets. Retrieved from Lisbon: http://www.emcdda.europa.eu/system/files/publications/2155/TDXD16001ENN_FINAL.pdf

European Monitoring Centre for Drugs and Drug Addiction and Europol. (2017). Drugs and the darknet: Perspectives for enforcement, research and policy. Retrieved from Luxembourg: https://www.europol.europa.eu/publicationsdocuments/drugs-and-darknet-perspectives-for-enforcement-research-and-policy

Europol. (2017). How illegal drugs) sustain organised crime in the EU. Retrieved from https://www.europol.europa.eu/publications-documents/how-illegal-drugs-sustain-organised-crime-in-eu

Felson, M., \& Clarke, C. (1998). Opportunity Makes the Thief: Practical theory for crime prevention. Retrieved from London: https://pdfs.semanticscholar.org/09db/dbce90b22357d58671c41a50c8c2f5dc1cf0.pdf

Fischer, B., Keates, A., Bühringer, G., Reimer, J., \& Rehm, J. (2014). Non-medical use of prescription opioids and prescription opioid-related harms: why so markedly higher in North America compared to the rest of the world? Addiction, 109(2), 177-181. doi:10.1111/add.12224

Forman, R. F., Woody, G. E., McLellan, T., \& Lynch, K. G. (2006). The Availability of Web Sites Offering to Sell Opioid Medications Without Prescriptions. American Journal of Psychiatry, 163(7), 1233-1238. doi:10.1176/ajp.2006.163.7.1233

Gelatti, U., Pedrazzani, R., Marcantoni, C., Mascaretti, S., Repice, C., Filippucci, L., . . . Feretti, D. (2013). 'You've got m@il: Fluoxetine coming soon!': Accessibility and quality of a prescription drug sold on the web. International Journal of Drug Policy, 24(5), 392-401. doi:10.1016/j.drugpo.2013.01.006

Han, B., Jones, C. M., Blanco, C., \& Compton, W. M. (2017). National trends in and correlates of nonmedical use of prescription stimulants, nonmedical use frequency, and use disorders. Journal of Clinical Psychiatry, 78(9), e125e1258. doi: $10.4088 / \mathrm{JCP} .17 \mathrm{~m} 11760$

Inciardi, J. A., Surratt, H. L., Cicero, T. J., Rosenblum, A., Ahwah, C., Bailey, J. E., . . Burke, J. J. (2010). Prescription drugs purchased through the internet: Who are the end users? Drug and Alcohol Dependence, 110(1), 21-29. doi:10.1016/j.drugalcdep.2010.01.015 
International Energy Control. (2019). ALERT: Update on adulterated samples of ALPRAZOLAM. Retrieved from https://energycontrol-international.org/alert-update-on-adulterated-samples-of-alprazolam/

International trade administration. (2016). 2016 Top Markets Report Pharmaceuticals. Retrieved from https://www.trade.gov/topmarkets/pdf/Pharmaceuticals_Executive_Summary.pdf

Kelly, B. C., Wells, B. E., Pawson, M., LeClair, A., \& Parsons, J. T. (2014). Combinations of prescription drug misuse and illicit drugs among young adults. Addictive Behaviors, 39(5), 941-944. doi:10.1016/j.addbeh.2013.12.003

Koenraadt, R., \& van de Ven, K. (2018). The Internet and lifestyle drugs: an analysis of demographic characteristics, methods, and motives of online purchasers of illicit lifestyle drugs in the Netherlands. Drugs: Education, Prevention and Policy, 25(4), 345-355. doi:10.1080/09687637.2017.1369936

Kruithof, K., Aldridge, J., Décary Hétu, D., Sim, M., Dujso, E., \& Hoorens, S. (2016). Internet-facilitated drugs trade: An analysis of the size, scope and the role of the Netherlands. Retrieved from Santa Monica: http://www.rand.org/pubs/research_reports/RR1607.html

Lavorgna, A. (2015). The online trade in counterfeit pharmaceuticals: New criminal opportunities, trends and challenges. European Journal of Criminology, 12(2), 226-241. doi:10.1177/1477370814554722

LegitScript. (2016). The Internet Pharmacy Market in 2016: Trends, Challenges, and Opportunities Retrieved from http://safemedsonline.org/wp-content/uploads/2016/01/The-Internet-Pharmacy-Market-in-2016.pdf

Levaggi, R., Orizio, G., Domenighini, S., Bressanelli, M., Schulz, P. J., Zani, C., ... Gelatti, U. (2009). Marketing and pricing strategies of online pharmacies. Health Policy, 92(2), 187-196. doi:10.1016/j.healthpol.2009.03.010

Levchenko, K., Pitsillidis, A., Chachra, N., Enright, B., Felegyhazi, M., Grier, C., . . Savage, S. (2011, 22-25 May 2011). Click Trajectories: End-to-End Analysis of the Spam Value Chain. Paper presented at the 2011 IEEE Symposium on Security and Privacy.

Mackey, T. K. (2018). Opioids and the Internet: Convergence of Technology and Policy to Address the Illicit Online Sales of Opioids. Health Services Insights, 11, 1-6. doi:10.1177/1178632918800995

Mackey, T. K., \& Nayyar, G. (2016). Digital danger: a review of the global public health, patient safety and cybersecurity threats posed by illicit online pharmacies. British médical bulletin, 118(1), 110-126. doi:10.1093/bmb/ldw016

Martin, J. (2014a). Drugs on the dark net: how cryptomarkets are transforming the global trade in illicit drugs: Palgrave Macmillan.

Martin, J. (2014b). Lost on the Silk Road: Online drug distribution and the 'cryptomarket'. Criminology and Criminal Justice, 14(3), 351-367. doi:10.1177/1748895813505234

Martin, J., \& Christin, N. (2016). Ethics in Cryptomarket Research. International Journal of Drug Policy, 35, 84-91. doi:10.1016/j.drugpo.2016.05.006

Martin, J., Cunliffe, J., Décary-Hétu, D., \& Aldridge, J. (2018). Effect of restricting the legal supply of prescription opioids on buying through online illicit marketplaces: interrupted time series analysis. BMJ, 361, 1-7. doi:10.1136/bmj.k2270

McCoy, D., Pitsillidis, A., Grant, J., Weaver, N., Kreinich, C., Krebs, B., . . Levchenko, K. (2012). PharmaLeaks: Understanding the business of online pharmaceutical affiliate programs. Paper presented at the 21st USENIX Security Symposium, Bellevue, WA.

Mignone, M., \& Novara, E. (2017). The illegal sale of medicines on the dark net. The case of benzodiazepines and prescription drugs on Alphabay. Retrieved from Torri di Quartesolo: https://www.npsproject.eu/reports/

Moosmann, B., Bisel, P., \& Auwärter, V. (2014). Characterization of the designer benzodiazepine diclazepam and preliminary data on its metabolism and pharmacokinetics. Drug Testing and Analysis, 6(7-8), 757-763. doi:10.1002/dta.1628

O'Hagan, A., \& Garlington, A. (2018). Counterfeit drugs and the online pharmaceutical trade, a threat to public safety. Forensic Science \& Criminology International Journal, 6(3), 151-158. doi:10.15406/frcij.2018.06.00200 
Olfson, M., King, M., \& Schoenbaum, M. (2015). Benzodiazepine Use in the United States. JAMA Psychiatry, 72(2), 136142. doi:10.1001/jamapsychiatry.2014.1763

Orsolini, L., Francesconi, G., Papanti, D., Giorgetti, A., \& Schifano, F. (2015). Profiling online recreational/prescription drugs' customers and overview of drug vending virtual marketplaces. Human Psychopharmacology: Clinical and Experimental, 30(4), 302-318. doi:10.1002/hup.2466

Paquet-Clouston, M., Décary-Hétu, D., \& Morselli, C. (2018). Assessing market competition and vendors' size and scope on AlphaBay. International Journal of Drug Policy, 54, 87-98. doi:10.1016/j.drugpo.2018.01.003

Rhumorbarbe, D., Staehli, L., Broséus, J., Rossy, Q., \& Esseiva, P. (2016). Buying drugs on a Darknet market: A better deal? Studying the online illicit drug market through the analysis of digital, physical and chemical data. Forensic Science International, 267, 173-182. doi:10.1016/j.forsciint.2016.08.032

Smith, M. D., \& Brynjolfsson, E. (2001). Consumer decision-making at an Internet shopbot: Brand still matters. Journal of Industrial Economics, 49(4), 541-558. doi:10.1111/1467-6451.00162

Soska, K., \& Christin, N. (2015). Measuring the longitudinal evolution of the online anonymous marketplace ecosystem. Paper presented at the 24th USENIX Security Symposium, Washington, D.C.

Sugiura, L. (2018). Respectable deviance and purchasing medicine online: Opportunities and risks for consumers: Palgrave Macmillan US.

United Nations Office on Drugs and Crime. (2011). The non-medical use of prescription drugs. Retrieved from New York: https://www.unodc.org/documents/drug-prevention-and-treatment/nonmedical-use-prescription-drugs.pdf

United Nations Office on Drugs and Crime. (2018). World Drug Report 2018. Retrieved from New York: https://www.unodc.org/wdr2018/

United Nations Office on Drugs and Crime. (September 2017). Global SMART Update. Non-medical use of benzodiazepines: a growing threat to public health? https://www.unodc.org/documents/scientific/Global_SMART_Update_2017_Vol_18.pdf

Van Buskirk, J., Naicker, S., Roxburgh, A., Bruno, R., \& Burns, L. (2016). Who sells what? Country specific differences in substance availability on the Agora cryptomarket. International Journal of Drug Policy, 35, 16-23. doi:10.1016/j.drugpo.2016.07.004

Van Buskirk, J., Roxburgh, A., Bruno, R., \& Burns, L. (2015). Drugs and the Internet. Retrieved from Sydney: https://ndarc.med.unsw.edu.au/sites/default/files/ndarc/resources/Drugs $\% 20 \% 26 \% 20 \mathrm{The} \% 20$ Internet $\% 20$ Issue $\%$ 204.pdf

Van Buskirk, J., Roxburgh, A., Bruno, R., Naicker, S., Lenton, S., Sutherland, R., . . Burns, L. (2016). Characterising dark net marketplace purchasers in a sample of regular psychostimulant users. International Journal of Drug Policy, 35 , 32-37. doi:10.1016/j.drugpo.2016.01.010

Van Hout, M. C., \& Bingham, T. (2013). 'Silk Road', the virtual drug marketplace: A single case study of user experiences. International Journal of Drug Policy, 24(5), 385-391. doi:10.1016/j.drugpo.2013.01.005

WHO. (2010). Bulletin of the World Health Organization 88(4), 241-320.

\section{Footnotes}

1 The last crawl is not always the third one as a listing might be removed from sale by the vendor.

2 United Nations, Department of Economic and Social Affairs, Population Division (2017). World Population Prospects:

The 2017 Revision, DVD Edition.

3 A colour is attributed to each country. The length of an arc represents the size of the flow and its direction is represented by the size of the gap between the circle and the flow; the smallest gap represents the origin of the flow and the largest gap 
its destination(s). The dimension of the arc is proportional to the number of listings counted for the original country to its destination.

4 Internet World Stats, https://www.internetworldstats.com/top25.htm (last seen 13/02/2019)

${ }_{5}$ See https://darknetmarkets.co/alphabay/ 